\title{
Factors Affecting Customer Satisfaction and Repurchase Intention: A Study of Full-Service Trendy Restaurants in Vietnam
}

\author{
Chen $\mathrm{Ho}^{1^{*}}$, Huei-Sheng $\mathrm{Tu}^{2}$, Nguyen Ngoc Anh3, Pham Minh Tuan ${ }^{4}$, Nguyen Thi \\ Ngoc Anh ${ }^{5}$, Phan Thi Minh $\mathrm{Ha}^{6}$
}

\author{
${ }^{1}$ Associate Professor, International Business \& Trade Program, Ming Chuan University, Taipei, Taiwan ${ }^{2}$ Assistant \\ Professor, International Business \& Trade Program, Ming Chuan University, Taipei, Taiwan ${ }^{3 \sim 6}$ International Business \& \\ Trade Program, Ming Chuan University, Taipei, Taiwan \\ "Corresponding author. Email: hochen@mail.mcu.edu.tw
}

\begin{abstract}
Trendy restaurants" have emerged in the food and beverage industry as the popularity of social media arose rapidly. For consumers enjoy sharing pictures or videos taken in restaurants, providing trendy space turned out to be an effective way of customer engagement. A growing number of consumers all over the world are always sharing their experiences as well as using these platforms to discover food and beverage trends. Among different parts of the world, Vietnam has a significant number of consumers, especially younger age, are considering social media platforms as a powerful medium in their decision-making. In order to explore the factors behind customer satisfaction at trendy restaurants, this study investigates narcissism personality together with food/drink and service quality as potential predictors to satisfaction and repurchase intention in Vietnamese fullservice trendy restaurants. Samples of 213 Vietnamese guests from trendy restaurants were surveyed. SPSS was used to analyze collected data and the findings point out that, in general, food quality, service quality and narcissism personality traits have significant impacts on customer satisfaction and repurchase intention. Customer satisfaction mediates the relationships between predictors and repurchase intention. The implications of these findings, limitations of the study and future research suggestions are also discussed.
\end{abstract}

Keywords: Social Media, Food Quality, Service Quality, Narcissism, Customer Satisfaction, Repurchase Intention, Vietnam,

Trendy Restaurant.

\section{INTRODUCTION}

Vietnamese cuisine has its international reputation as diversity and abundance of food culture. The variety in culinary culture comes not only from the North to the South but also from Europe to the American. In recent years, food culture has become a crucial factor in which the government is exceptionally interested in economic development, and it is used as a method to attract tourists. At the same time, considered as a global social trend,
"Trendy Restaurant" rapidly booms and spreads out in manycountries.

The word "Trendy" had appeared and represented for the young generation in Vietnam and has been mentioned as the synonym of modern, popular, fashionable, youthful, and dynamic. According to Barber et al. [1], the customer patronage behaviors depend on the way they classify the restaurant. A restaurant is considered to be a "luxury restaurant" or "ordinary restaurant" relies on the money that customers pay for each meal. In 2018, when young people used social media for food-related 


\section{Procedia Business and Financial Technology}

Proceedings of the 2nd International Conference on Business and M anagement of T echnology (ICO N BM T 2020) - Part 2

activities: 69 percent of users have uploaded their food photos to social media, 26 percent have taken more than ten photos to get one perfect picture that matches their beautiful feed [2].

This research was conducted in Ho Chi Minh City, Vietnam. We chose Vietnam market because of its urbanization and substantial population growth, along with the size of the market whose population is over 97 million people in general and over 12 million in Ho Chi Minh city which is proposed to be the highest GDP per capita city (US\$ 6,389/one person) in 2018 and expected to reach US\$ 9,800/one person in 2020. Besides, half of the Vietnamese population is under thirty years old. Young people were the main contributor to this industry's development. According to Euromonitor [3], Vietnam's hotel, restaurant, and institutional food service industry included 85,000 full-service restaurants in 2013, and Vietnam's food service market is forecasted to reach 65.03 billion USD by 2024 [4]. Eating outside is considered as a part of young Vietnamese culture due to the influence of modern Western lifestyles. Dining out is no longer just for special occasions. The young generation enjoys hanging out, celebrating, gathering to talk with friends or their relatives, trying new dishes, or even having work discussion at the restaurant. Ho Chi Minh city has a big group of profound- knowledge young customers towards dining out, which stands for 16,000 people and they spend up to a third of their monthly wage for only eating out [4].

\subsection{Significance \& Research Questions}

This study explores the factors affect customer satisfaction and retention in full-service trendy restaurants. Research findings will help Vietnamese restaurants to maintain a better relationship with loyal customers and acquire new customers for business growth and sustainability. The purpose of this study is to use customers' expectations to develop a synopsis model for improving service quality in general and advancing customer satisfaction and retention in particular. Customers would like to go back to a restaurant where they are treated specially and their expectations were met. Meanwhile, personality could be an interesting predictor. For customers who enjoy showing off their life on social media, dining out at a trendy restaurant is a good story to tell. Therefore, we identified narcissism personality trait to be a potential predictor in the research framework. We tried to answer these two research questionse:

1). What are the main factors that influence customer satisfaction among trendy restaurant?

2). Is narcissistic personality trait an important factor with impacts on customer satisfaction and repurchase intention among trendyrestaurants?

\section{LITERATURE REVIEW}

\subsection{Customer Satisfaction}

$76 / 180$

Customer satisfaction is an emotional state for service products that have been used [5]. Bachelet [6] defines customer satisfaction as an emotional response of customers responding to their experience with a product or service. Customer satisfaction is the level of a person's sensory reception state concluded from the comparison of results obtained from the consumption of products/services with his or her expectations [7]. In general, researchers consider satisfaction as feeling pleasing and comfortable when customers are responding to their expectations of product or service. According to several researches, quality of food and services have a directly proportional relationship with customer satisfaction, which both food and service quality are the cause, and satisfaction is the result [8].

According to Torres and Kline [9], the better changes in influencing consumer behaviors are provided when the employees have adequate knowledge to evaluate customers' satisfaction. Yee, et al. [10] also declared that customers repeatedly patronized particular services if their demand is fulfilled. Service quality intimately associates with customer satisfaction and customer satisfaction and is positively related to customer loyalty [11]. Moreover, Parasuraman et al[12] indicated that retention, word of mouth, and satisfaction all have a significant effect on customers' cognizance of service quality.

\section{$2.2 \quad$ Food and Beverages Quality}

Food and Beverages quality can be described as aspects of food that are acceptable to consumers [13]. This involves many factors such as nutrition quality, appearance, size, shape, color, gloss, and consistency, texture, and flavor. Following Ryu et al. [14], Food quality is seen as the scale for evaluating consumer satisfaction in the restaurant market, which resulted in five dimensions of food quality: the smell of the food is eye-catching, a wide variety of foods are available, food is nutritious, food is delicious, and food is fresh. Food and Beverages quality has a significant impact on restaurant brand image [15] [16] [17]. Sulek and Hensley [18] insist that food quality is a critical circumstance for the customer when choosing a restaurant. The memorable and delicious taste of the food is the main reason motivating customers to revisit the restaurant [19].

\section{H1: There is a relationship between food and beverage quality and customer satisfaction.}

\subsection{Service Quality}

Services are actions beneficial to the customers and can be defined in various ways. Services are considered operations, processes, methods of implementation by 


\section{Procedia Business and Financial Technology}

Proceedings of the 2nd International Conference on Business and M anagement of T echnology (ICO N BM T 2020) - Part 2

suppliers to create value for customers to meet their needs and expectations [20]. According to the SERVQUAL framework [12], one of the major elements of service quality is comfortable atmosphere. The decor of the restaurant is not only a hot, exciting topic for the restaurant' owners, but also an endless discussion of young people who are interested in posting their photos on social media [21]. The decoration, atmosphere, furniture and other decorating items also affect the customer experience when dining out and the attitude when returning to purchase [22]; [23]. Moreover, customer purchase behavior roughly increases 12 percent on average if they enjoy the joyfulness and provocation surrounding [23].

Another important element of SERVQUAL is employee behavior. Gazzol et al. [24] concluded that employees have a significant positive effect on the service industry and they also have an influence on customers' perceptions of service quality. Staff who is excited and enjoyed their work give warm greetings and show their friendliness to customers also attain customers' high satisfaction and valuation [25]; [21]; [26]. Therefore, the following hypothesis is proposed:

\section{H2: There is a relationship between service quality and customer satisfaction}

\subsection{Narcissistic personality trait}

Narcissism is described as a characteristic of someone who has self-interest, pride, and coercion. Narcissists have supercilious and impractical views about what they can do. They often fail to give any interest but tend to expect attention from others, which also indicates a lowlevel concern to the community, group ideals, teamwork, and social skills [27]. They seek for material wealth [28] and have high economic ambitions [29] than other ordinary people. Likewise, they tend to obtain highquality and luxurious items that reflect their prestige and elegance. Overall, people with narcissism is a crucial target customer for restaurant, especially restaurant that invests on brand image [30]. In marketing decisions, the impact of self-related motivations is expected to increase. With that being said, various personality traits such as self-esteem and self-conceptual clarity manipulated the effect of self- associated motivations on consumer behavior [31]. From a survey from the Pew Research Center, more and more people addicted to social media (Instagram, Facebook, Twitter, etc.). Nearly half of Vietnam's online population (48\%) use social media as a source for updating the current trends at least once a day. This included $81 \%$ of the young adult (18-29 years old), $44 \%$ of the middle-age (30-49 years old), and just $3 \%$ of 50 year olds and older. People (mostly young generation) are continually posting their emotion, location, pictures online to ostentatious their fancy lifestyle, from which help them gaining satisfaction from the attention and admiration of others [32]. Therefore, the following hypothesis is proposed:

\section{H3: There is a relationship between narcissistic personal trait and customer satisfaction.}

\subsection{Repurchase Intention}

Nowadays, customers are one of the main factors determining the success of a business. For that reason, conducting a study on customer satisfaction in the restaurant industry system is extremely necessary for the restaurant to attain a more significant market share. In general, dining out in trendy restaurants can be understood in two stages. The first stage is originally cared about encouraged customers to go to trendy restaurants, buying food, beverage and services available and the second is to stir up them to repeated patronized particular trendy restaurants. Customer buyback intention is considered to be an effective way to attain potential advantages [33]. The restaurant industry is becoming more and more dramatically competitive due to the increasingly diverse suppliers and the significant rise in customers' demand for better quality. Every single trendy restaurant in the market is now faced with elimination if they cannot define themselves to meet customer expectations and identify an appropriate business strategy in each section of doing business. Kim et al. [34] figured out that shopping satisfaction is the most substantial factor that takes effect on customer repurchase intention and restaurant-selected decisions.

H4: There is a relationship between customer satisfaction and customer repurchase intention.

\subsection{Customer Satisfaction being a Mediator}

According to Mattila [35], food quality was the most essential attributor of overall restaurant aspects and in our research, it is considered to have a positive relationship with customer satisfaction. Furthermore, when the restaurant was researched by many other experts, they concluded determinants of dining satisfaction and found that service quality influenced customer satisfaction [36] [37]. A better service quality creates customers the desire to keep repeatedly patronized a particular trendy restaurant and makes greater repurchase intentions among them. According to Wang et al. [38], the mediating role of Attitude and Perceived Behavioral Control is considered for further consolidating the comprehensive analysis understanding. For that reason, the mediating variable is consumer satisfaction. Food quality, service quality, and Narcissism are independent variables. customer repurchase Intention is the dependent variable in our study. But between them, there is an 


\section{Procedia Business and Financial Technology}

Proceedings of the 2nd International Conference on Business and M anagement of T echnology (ICO N BM T 2020) - Part 2

interconnection relationship with each other.

H5: Customer satisfaction mediates the relationships between 3 factors (food and beverage quality, service quality, narcissistic personality trait) and repurchase intention.

\section{METHODOLOGY}

\subsection{Research Framework}

Food and beverage quality, service quality, narcissistic personality trait are the three independent variables and the dependent variable customer satisfaction. Besides, there also has an independent variable is customer satisfaction and the dependent variable is repurchase intention.

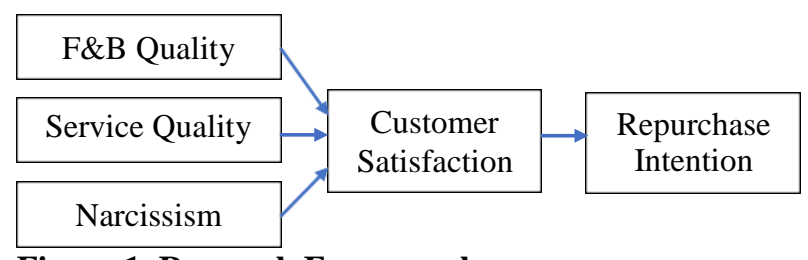

Figure 1. Research Framework

\subsection{Research Design \& Sampling}

We conducted a quantitative research in Vietnam, a very potential market in Ho Chi Minh City-Vietnam's economic hub-and we've focused on full-service trendy restaurants, which are an attractive among young generation. As we consider the trendy concept of restaurants, we choose some restaurants that are also popular. A "classic restaurant" typically concentrates on contemporary visual decor and presentation of food. The restaurants draw more young customers by investing in the physical environment. The food served by a "trendy restaurant" will cost its customers more than the food on the street. Our study was focused not only on a description of a trendy restaurant but also on the international news (QuartZ news) or Blogspot, such as Pizza 4P's, Haidilao Hotpot, Gogi House, L'usine, etc.

\subsection{Data Collection}

An experimental questionnaire was conducted on the online survey platform. In the beginning, we provided short briefing about the trendy restaurants. Most of the survey questions are about respondents' perception of that occupy approximately 76 percent of the total.

More than 60 percent of respondents eating out in trendy restaurants quite often. 155 respondents also agreed that they decide to eat out in trendy restaurants based on their friend's or relatives'recommendations. Up to 102 respondents decided to dine-out in trendy restaurants after food and beverages quality, service quality, and their narcissism personality traits. The questionnaires are provided in both Vietnamese and English. The survey link was distributed online. At the end of data collection, we collected 213 responses with valid sample of 200 responses.

\subsection{Measurements}

There are totally 40 questions in our survey. Except 7 demographic and behavioral questions in the beginning, see

Table 1 for the details of other 33 survey items and their sources. Five-point Likert scale is applied to all survey questions.

Table 1. Constructs and Measures

\begin{tabular}{|l|l|l|}
\hline \multicolumn{1}{|c|}{ Constructs } & $\begin{array}{l}\text { \# of } \\
\text { Items }\end{array}$ & \multicolumn{1}{c|}{ Sources of Measures } \\
\hline $\begin{array}{l}\text { Food \& Beverage } \\
\text { Quality (F\&B) }\end{array}$ & 3 & $\begin{array}{l}\text { Amin et al., (2013); } \\
\text { Mohsin \& Lockyer (2010) }\end{array}$ \\
\hline $\begin{array}{l}\text { Service Quality (SQ) } \\
\text { Narcissistic }\end{array}$ & 9 & $\begin{array}{l}\text { Parasuraman et al. } \\
(1988) \text {; Qin \& Prybutok } \\
\text { (2009) }\end{array}$ \\
\hline $\begin{array}{l}\text { Personality Trait (NA) } \\
\text { Customer Satisfaction } \\
\text { (CS) }\end{array}$ & 4 & Raskin \& Terry (1988) \\
\hline $\begin{array}{l}\text { Repurchase Intention } \\
\text { (RI) }\end{array}$ & 4 & $\begin{array}{l}\text { Westbrook \& Oliver } \\
(1991) ; \text { Jani \& Han (2011) }\end{array}$ \\
\hline
\end{tabular}

\section{RESULTS}

\subsection{Respondents}

In total, 200 valid responses were collected in a month. The majority of participants are females, accounting for 70 percent. Seventy-eight percent of the respondents are in the group between 21 and 30 years old. The group under 20 years old is the second largest, which accounts for 16 percent. In terms of monthly income, the majority of respondents are receiving monthly income from 3 to 5 million VND ( 129-215 USD), with a percentage of 29.5 percent. The participants who earn under 3 million VND (<129 USD) per month accounts for 21 percent. As for educational background, 153 respondents are university and college students. They are also the majority group watching or reading reviews of famous food bloggers and influencers on social media platforms. Up to 155 respondents keep coming back to trendy restaurants because of the delicious food. Moreover, good service quality and reasonable prices are the top reasons when they decide to repeatedly patronize a particular trendy 


\section{Procedia Business and Financial Technology}

Proceedings of the 2nd International Conference on Business and M anagement of T echnology (ICO N BM T 2020) - Part 2

restaurant.

\subsection{Reliability \& Correlations}

All the scales have shown good reliability when the values of items in the range between 0.7 and 0.9 . In Table 2, the Pearson's correlation matrix shows the relationships between research constructs. The correlation between customer satisfaction and repurchase intention is strong $(\mathrm{r}=0.813 * *)$. The second strongest correlation occurs between service quality and customer satisfaction $\left(\mathrm{r}=0.706^{* *}\right)$.

Table 2. Reliability \& Correlation Matrix

\begin{tabular}{|l|r|r|r|r|r|r|r|c|}
\hline Scale & Alpha & Mean & SD & 1 & 2 & 3 & 4 & 5 \\
\hline 1.F\&B Quality (FB) & 0.777 & 4.005 & 2.018 & - & & & & \\
\hline 2.Service Quality (SQ) & 0.896 & 4.057 & 5.408 & $0.609^{* *}$ & - & & & \\
\hline 3.Narcissism (NA) & 0.811 & 3.316 & 7.333 & $0.231^{* *}$ & $0.372^{* *}$ & - & & \\
\hline 4.Customer Satisfaction (CS) & 0.911 & 4.042 & 2.928 & $0.644^{* *}$ & $0.706^{* *}$ & $0.254^{* *}$ & - & \\
\hline 5.Repurchase Intention (RI) & 0.891 & 3.825 & 3.347 & $0.592^{* *}$ & $0.611^{* *}$ & $0.306^{* *}$ & $0.813^{* *}$ & - \\
\hline
\end{tabular}

Note: Pearson's Correlation: Construct correlation is significant (two-tailed) with $* *=p<.01$

\subsubsection{Simple Regression}

In Table 3, it demonstrates how customer satisfaction is affected by independent variables. Statistics show that all three independent variables (FB, SQ, NA) have significant impact on customer satisfaction. The relationship between customer satisfaction and repurchase intention is also significant.

\subsubsection{Mediation Test}

Following the procedure suggested by Baron and Kenny's, there has three requirements to prove customer satisfaction is a mediator. Firstly, two out of three independent variables are associated with repurchase intention (Table 4, Model 1).

Secondly, all three independent variables are associated with customer satisfaction, the potential mediator (Table $3)$.

Thirdly, customer satisfaction is associated with repurchase intention (Table 4). In Table 4 (Model 2), we added customer satisfaction into the equation as another independent variable. Service quality (from $p=0.000$ to $p=0.061$ ) and narcissism (from $p=0.000$ to $p=0.971$ ) are no longer significantly associated with repurchase intention due to the mediating effect of customer satisfaction.

Based on the findings in both Table 3 and Table 4, food $\&$ beverage quality has strong impact on customer satisfaction but does not have direct impact on repurchase intention. Both service quality and narcissism need to go through the mediator in order to affect repurchaseintention.

Moreover, customer satisfaction has strong impact on repurchase intention even with all other predictors considered $(p=0.924$ in Table $3 \& p=0.719$ in Table 4 , $\mathrm{p}<0.01)$. Therefore, we can conclude that customer satisfaction does mediate the relationships between two predictors with dependent variable. This finding provides partial support for Hypothesis 5 


\section{Procedia Business and Financial Technology}

Proceedings of the 2nd International Conference on Business and M anagement of T echnology (ICO N BM T 2020) - Part 2

Table 3. Simple Regression Testing Hypothesis 1, 2, 3, 4

\begin{tabular}{|c|c|c|c|c|c|c|c|c|}
\hline $\begin{array}{l}\text { Pependent } \\
\text { Variable }\end{array}$ & dependent Variables & B & SEB & $\mathrm{p}$ & $\mathrm{t}$ & \multicolumn{2}{|c|}{$\begin{array}{c}\text { p- value egression } \\
\text { Results }\end{array}$} & $\begin{array}{l}\text { Hypothesis } \\
\text { Acceptance }\end{array}$ \\
\hline \multirow{3}{*}{$\begin{array}{c}\text { Customer } \\
\text { Satisfaction (CS) }\end{array}$} & $\begin{array}{c}\text { Food \& Beverage } \\
\text { Quality (FB) }\end{array}$ & .705 & .06 & $.644 * *$ & 11.834 & .000 & $\begin{array}{l}\mathrm{R}^{2}=.414 \\
\mathrm{~F}=140.052\end{array}$ & H1: Supported \\
\hline & Service Quality (SQ) & .863 & .061 & $.706^{* *}$ & 14.032 & .000 & $\begin{array}{l}\mathrm{R}^{2}=.499 \\
\mathrm{~F}=196.892\end{array}$ & H2: Supported \\
\hline & $\begin{array}{c}\text { Narcissism Personality } \\
\text { Trait (NA) }\end{array}$ & .332 & .09 & $.254 * *$ & 3.692 & .000 & $\begin{array}{l}\mathrm{R}^{2}=.064 \\
\mathrm{~F}=13.629\end{array}$ & H3: Supported \\
\hline \begin{tabular}{|l} 
Repurchase \\
Intention (RI)
\end{tabular} & r Satisfaction (CS) & .924 & .047 & $.813 * *$ & 19.664 & .000 & $\begin{array}{c}\mathrm{R}^{2}=.661 \\
\mathrm{~F}=386.663\end{array}$ & H4: Supported \\
\hline
\end{tabular}

Note: $* p<0.05$, ** $p<0.01$

Table 4. Regression between independent variables (FB, SQ, NA) and mediating variable (CS) and dependent variable $(\mathbf{R I})$

\begin{tabular}{|c|c|c|c|c|c|c|c|}
\hline Independent Variable & B & SEB & $\mathrm{p}$ & $\mathrm{t}$ & $\mathrm{p}$ & VIF & \\
\hline \multicolumn{8}{|l|}{ MODEL 1} \\
\hline (Constant) & -.420 & .355 & & -1.184 & .238 & & \multirow{4}{*}{$\begin{array}{l}\mathrm{R}^{2}=.457 \text { Adj. } \\
\mathrm{R}^{2}=.448 \\
\mathrm{~F}=54.89\end{array}$} \\
\hline Food and Beverages Quality (FB) & .134 & .084 & .090 & 1.587 & .114 & 1.161 & \\
\hline Service Quality (SQ) & .434 & .083 & .349 & 5.254 & .000 & 1.589 & \\
\hline Narcissistic Personality Trait (NA) & .506 & .097 & .365 & 5.242 & .000 & 1.746 & \\
\hline \multicolumn{8}{|l|}{ MODEL 2} \\
\hline (Constant) & -.507 & .274 & & -1.851 & .066 & & \multirow{5}{*}{$\begin{array}{c}\mathrm{R}^{2}=.678 \text { Adj. } \\
\mathrm{R}^{2}=.672 \mathrm{~F}=102.843\end{array}$} \\
\hline Food \& Beverages Quality (FB) & .147 & .065 & $.099 *$ & 2.259 & .025 & 1.161 & \\
\hline Service Quality (SQ) & .13 & .069 & .104 & 1.884 & .061 & 1.858 & \\
\hline Narcissism Personality Trait (NA) & .003 & .086 & .002 & 0.037 & .971 & 2.338 & \\
\hline Customer Satisfaction (CS) & .817 & .07 & $.719 * *$ & 11.598 & .000 & 2.333 & \\
\hline
\end{tabular}

Note: $* p<0.05, * * p<0.01$, Dependent Variable: Repurchase Intention (RI)

\section{DISCUSSION}

The results clearly pointed out that people chose to go to dine- out in trendy restaurants mostly because of the delicious food. Moreover, good service quality and affordable prices are also one of the top priorities when they decide to repeatedly patronize a particular trendy restaurant. Customers with higher narcissistic traits tend to have higher customer satisfaction at trendy restaurants. Customer satisfaction plays critical role in determining repurchase intention. These findings indicate that all three predictors may have a higher chance of meeting customer satisfaction and lead them to think about repurchase in thefuture.

Hypothesis 1 is supported by the results showing that food quality has impact on customer satisfaction. This finding is comparable to several research in which food quality was one of the most important factors for enhancing customer satisfaction [39]. Additionally, Hypothesis 2 is also directly supported. The results show that service quality has a positive relationship over customer satisfaction. Similar to the study by Gazzol et al. [24], perceived service quality has been found to have an impact on customer's satisfaction. If the service quality cannot be delivered up to customers' expectations, the perception of customer satisfaction would be low.

Furthermore, Hypothesis 3 is supported showing a direct relationship between narcissism and customer satisfaction. Even the explanatory power of narcissism is smaller than the power of other two predictors (FB and $\mathrm{SQ}$ ), it is still significantly associated with customer satisfaction at trendy restaurants. Among all three predictors, service quality has the strongest impact on customer satisfaction, and food quality comes second. Consistent with previous literatures, customer satisfaction is critical to repurchase intention [40] [41].

Moreover, we proved that customer satisfaction is a mediator between two predictors (SQ and NA) and repurchase intention. The mediation between food and beverage quality and repurchase intention was not found. 


\section{Procedia Business and Financial Technology}

Proceedings of the 2nd International Conference on Business and M anagement of T echnology (ICO N BM T 2020) - Part 2

We can conclude that food and beverage quality is important to customer satisfaction but does not determine repurchase intention alone. For trendy restaurants, service quality still overrides other two predictors. Customers with high narcissistic personality will return to the same trendy restaurants if they were satisfied with their overall experiences there.

\section{$5.1 \quad$ Limitation \& Future Studies}

The first limitation we encountered during data collection is the pandemic in the beginning of 2020. Therefore, we can only share survey link through social media and invite Vietnamese citizens to participate. If we could meet respondents in person, we would be able to collect more responses and explain our research purpose more clearly with a personal touch. The majority of our respondents are between 20 to 30 years old. We could have collected more from other age groups if we could approach respondents directly. The second limitation is the restriction on the area of the survey to the survey audience. Since the majority of the trendy restaurants are only available in metropolitan areas and our respondents mostly live in Ho Chi Minh City, our findings might not represent entire Vietnamese market. Finally, narcissism is still a new concept in similar studies. There are very few previous literatures supporting our assumption. All participants responded to our survey based

on their trendy restaurant experiences. We cannot compare the responses coming from people who go to normal restaurants (non-trendy).

Based on the study limitations, we developed several suggestions for future scholars. It is strongly recommended that future researchers spread the survey randomly and gather as much data as possible, thereby generating more reliable results that maybe the trend of the entire country. Due to our group survey, the reliability of our findings was mostly limited due to acquaintances around our life cycle. Secondly, we propose that further researchers develop a more qualitative question to accurately measure the need for customer engagement to achieve an optimal level of reliability in their purpose. It is hoped that using research with more qualitative questions would give a clearer picture of the intention to purchase and repurchase. This study could be extended into a focus group for in-depth discussions.

Finally, this research only focuses on trendy restaurant. Future research can focus on other service-based industries with potential impacts coming from customer's personality traits and social media behaviors.

\section{REFERENCES}

[1] N. Barber, R. J. Goodman, and B. K. Goh, "Restaurant consumers repeat patronage: A service quality concern," International Journal of
Hospitality Management, vol. 30, no. 2, pp. 329336, 2011.

[2] M. E. houp, "A year in food: Survey reveals millennials' eating and spending habits, Food Navigator-USA.COM." Aug. 28, 2019. [Online]. Available:

https://shorturl.at/MSV78habits?utm_source=cop yrig

[3] E. International, "Full-Service Restaurants in Vietnam." 2020.

[4] K. Das, "Growing Food \&Beverage Sector in Vietnam, Vietnam Briefing." Oct. 11, 2017. [Online]. Available: https://shorturl.at/lsIV3.

[5] R. A. eng and R. D. Mackoy, "An Empirical Examination of a Model of Perceived Service Quality and Satisfaction," Journal of Retailing, vol. 72, no. 2, pp. 201-214, 1996.

[6] D. Bachelet, "Measuring Satisfaction; or the Chain. the Tree, and the Nest," International Journal of Contemporary HospitalityManagement, 1995.

[7] P. Kotler and G. Armstrong, Principlesof Marketing, 10th ed. New Jersey: Pearson-Prentice Hall, 2004.

[8] P. Gupta and R. Srivastava, "Analysis of Customer Satisfaction in Hotel Service QualityUsing Analytic Hierarchy Process (AHP," International Journal of Industrial Engineering Research and Development (IJIERD, vol. 2, no. 1, pp. 59-68, 2011.

[9] E. Torres and S. F. Kline, "From customer satisfaction to customer delight: Creating a new standard of service for the hotel industry," International Journal of Contemporary Hospitality Management, vol. 25, no. 5, pp. 642-659, 2013.

[10] R. W. Y. Yee, A. C. L. Yeung, and E. T. C. Cheng, "An empirical study of employee loyalty, service quality and firm performance in the service industry," International Journal of Production Economics, vol. 124, no. 1, pp. 109-120, 2010.

[11] K. M. Siddiqi, "Interrelations between Service Quality Attributes, Customer Satisfaction and Customer Loyalty in the Retail Banking Sector in Bangladesh," International Journal of Business and Management, vol. 6, no. 3, pp. 12-36, 2011.

[12] A. Parasuraman, V. A. Zeithaml, and L. L. Berry, "SERVQUAL: A Multiple-Item Scale for Measuring Consumer Perceptions of Service Quality," Journal of Retailing, vol. 64, pp. 12-40, 1988.

[13] M. Ferree, "What is food quality?," Journalof Food Distribution Research, vol. 4, no. 2-3, pp. 34-36, 1973.

[14] K. Ryu, H. R. Lee, and W. G. Kim, "The influence of the quality of the physical environment, food, and service on restaurant image, customer perceived value, customer satisfaction, 


\section{Procedia Business and Financial Technology}

Proceedings of the 2nd International Conference on Business and M anagement of T echnology (ICO N BM T 2020) - Part 2

andbehavioral intentions," International Journal of Contemporary Hospitality Management, vol. 24, no. 2, pp. 200-223, 2012.

[15] F. Selnes, "An Examination of the Effect of Product Performance on Brand Reputation, Satisfaction and Loyalty"," European Journal of Marketing, vol. 27, no. 9, pp. 19-35, 1993.

[16] J. Tam, "Customer satisfaction, service quality and perceived value: An integrative model," Journal of Marketing Management, vol. 20, no. 7, pp. 897917, 2004.

[17] R. Kisang, L. Hye-Rin, and G. K. Woo, "The influence of the quality of the physical environment, food, and service on restaurant image, customer perceived value, customer satisfaction, andbehavioral intentions," International Journal of Contemporary Hospitality Management, vol. 24, no. 2, pp. 200-223, 2012.

[18] J. M. Sulek and R. L. Hensley, "The Relative Importance of Food, Atmosphere, and Fairness of Wait: The Case of a Full-service Restaurant," Cornell Hotel and Restaurant Administration Quarterly, vol. 45, no. 3, pp. 235-247, 2004.

[19] A. M. Susskind and E. K. Chan, "How Restaurant Features Affect Check Averages: A Study of the Toronto Restaurant Market," Cornell Hotel and Restaurant Administration Quarterly, vol. 41, no. 6, pp. 56-63, 2000.

[20] V. A. Zeithaml and M. J. Bitner, Services Marketing: Integrating Customer Focus across the Firm, 2nd ed. Boston: McGraw-Hill, 2000.

[21] E. A. Wall and L. L. Berry, "The combined effects of the physical environment and employee behavior on customer perception of restaurant service quality," Cornell Hotel and Restaurant Administration Quarterly, vol. 48, pp. 59-69, 2007.

[22] F. A. Sloan and J. G. Trogdon, "The impact of the master settlement agreement on cigarette consumption," Journal of Policy Analysis and Management, vol. 23, no. 4, pp. 843-855, 2004.

[23] K. Ryu and S. C. Jang, "Intention to experience local cuisine in a travel destination: The modified theory of reasoned action," Journal of Hospitality \& Tourism Research, 2006, doi: 10.1177/1096348006287163.

[24] G. Gazzol, I. M. Hancer, and B. Kim, "Explaining why employee-customer orientation influences customers' perceptions of the service encounter," Journal of Service Management, vol. 24, no. 4, pp. 382-400, 2013.

[25] C. Kuo and S. Hsiao, "A perspectives comparison: The importance and features of service attitude between international hotel employees and guests," The Journal of International Management Studies, vol. 8, no. 2, pp. 35-44, 2013.
[26] C. N. K. Naik, S. B. Gantasala, and G. V. Prabhakar, "SERVQUAL, customer satisfaction and behavioural intentions in retailing," European Journal of Social Sciences, vol. 17, no. 2, pp. 200 213, 2010.

[27] S. Z. Cisek, C. Sedikides, and C. M. Hart, "Do narcissists use material possessions as a primarybuffer against pain?," Psychological Inquiry, vol. 19, no. 3-4, pp. 205-207, 2008.

[28] P. Cohen and J. Cohen, "LifeValues and Adolescent Mental Health," Mahwah, NJ:Erlbaum, 1996.

[29] B. W. Roberts and R. W. Robins, "Broad dispositions, broad aspirations: The intersection of personality traits and major life goals," Personality \& Social Psychology Bulletin, vol. 26, pp. 12841296, 2000.

[30] M. L. Richins, "Special possessions and the expression of material values," Journal of Consumer Research, vol. 21, no. 3, pp. 522-533, 1994.

[31] D. Dunning, "Self-image motives and consumer behavior: How sacrosanct self-beliefs swaypreferences in the marketplace," Journal of Consumer Psychology, vol. 17, no. 4, pp. 237-249, 2007.

[32] P. Linh, "Snapshot of attitudes towards social media and online ads," Vietnam Economic Times, Oct. 2019, [Online]. Available: http://vneconomictimes.com/article/business/snap shot-

[33] H. T. Tsai and H. C. Huang, "Determinants of erepurchase intentions: an integrative model of quadruple retention drivers," Information \& Management, vol. 44, no. 3, pp. 231-239, 2007.

[34] J. Kim, B. Jin, and J. L. Swinney, "The role of etail quality, e-satisfaction and e-trust in online loyalty development process," Journal of Retailing and Consumer Services, vol. 16, pp. 239-247, 2009.

[35] A. Mattila, "Emotional bonding and restaurant loyalty," The Cornell Hotel and Restaurant Administration Quarterly, vol. 42, no. 6, pp. 7379, 2001.

[36] R. Ladhari, N. Souiden, and I. Ladhari, "Determinants of loyalty and recommendation: The role of perceived service quality, emotional satisfaction and image," Journal of Financial Services Marketing, vol. 16, pp. 111-124, 2011.

[37] Y. Liu and S. Jang, "Perceptions of Chinese restaurants in the U.S.: What affects customer satisfaction and behavioral intentions?," International Journal of Hospitality Management, vol. 28, no. 3, pp. 338-348, 2009.

[38] Y. Wang, Q. Min, and S. Han, "the effects of trust and risk on individual behavior toward social 


\section{Procedia Business and Financial Technology}

Proceedings of the 2 nd International Conference on Business and M anagement of T echnology (ICON BM T 2020) - Part 2

media platforms: A meta- analysis of the empirical evidence," Computers in Human Behavior, vol. 56, pp. 34-44, 2016.

[39] M. Haghighi and A. Dorostil, "\& Rahnama, A.(2012). Evaluation of factors affecting customer loyalty in the restaurant industry," African Journal of Business Management, vol. 6, no. 14, pp. 50395046.
[40] R. T. Rust and A. J. Zahorik, "satisfaction, customer retention, and market share," Journal of Retailing, vol. 69, pp. 193-215, 1993.

[41] H. Han and W. Kim, "Outcomes of relational benefits: Restaurant customers' perspective," Journal of Travel \& Tourism Marketing, vol. 26, no. 8, pp. 820-835, 2009. 